\title{
Differential sensitivity of oxidative and glycolytic muscles to hypoxia-induced muscle atrophy
}

Citation for published version (APA):

de Theije, C. C., Langen, R. C., Lamers, W. H., Gosker, H. R., Schols, A. M., \& Koehler, S. E. (2015). Differential sensitivity of oxidative and glycolytic muscles to hypoxia-induced muscle atrophy. Journal of Applied Physiology, 118(2), 200-211. https://doi.org/10.1152/japplphysiol.00624.2014

Document status and date:

Published: 15/01/2015

DOI:

10.1152/japplphysiol.00624.2014

Document Version:

Publisher's PDF, also known as Version of record

Document license:

Taverne

\section{Please check the document version of this publication:}

- A submitted manuscript is the version of the article upon submission and before peer-review. There can be important differences between the submitted version and the official published version of record.

People interested in the research are advised to contact the author for the final version of the publication, or visit the DOI to the publisher's website.

- The final author version and the galley proof are versions of the publication after peer review.

- The final published version features the final layout of the paper including the volume, issue and page numbers.

Link to publication

\footnotetext{
General rights rights.

- You may freely distribute the URL identifying the publication in the public portal. please follow below link for the End User Agreement:

www.umlib.nl/taverne-license

Take down policy

If you believe that this document breaches copyright please contact us at:

repository@maastrichtuniversity.nl

providing details and we will investigate your claim.
}

Copyright and moral rights for the publications made accessible in the public portal are retained by the authors and/or other copyright owners and it is a condition of accessing publications that users recognise and abide by the legal requirements associated with these

- Users may download and print one copy of any publication from the public portal for the purpose of private study or research.

- You may not further distribute the material or use it for any profit-making activity or commercial gain

If the publication is distributed under the terms of Article $25 \mathrm{fa}$ of the Dutch Copyright Act, indicated by the "Taverne" license above, 


\title{
Differential sensitivity of oxidative and glycolytic muscles to hypoxia-induced
} muscle atrophy

\author{
C. C. de Theije, ${ }^{1,2}$ R. C. J. Langen, ${ }^{1,3}$ W. H. Lamers, ${ }^{1,2}$ H. R. Gosker, ${ }^{1,3}$ A. M. W. J. Schols, ${ }^{1,3}$ \\ and S. E. Köhler ${ }^{1,2}$ \\ ${ }^{1}$ NUTRIM School for Nutrition, Toxicology and Metabolism, Maastricht University Medical Center+, Maastricht, \\ The Netherlands; ${ }^{2}$ Department of Anatomy and Embryology, Maastricht University Medical Center + , Maastricht, \\ The Netherlands; and ${ }^{3}$ Department of Respiratory Medicine, Maastricht University Medical Center+, Maastricht, \\ The Netherlands
}

Submitted 11 July 2014; accepted in final form 20 November 2014

de Theije CC, Langen RC, Lamers WH, Gosker HR, Schols AM, Köhler SE. Differential sensitivity of oxidative and glycolytic muscles to hypoxia-induced muscle atrophy. J Appl Physiol 118: 200-211, 2015. First published November 26, 2014; doi:10.1152/japplphysiol.00624.2014.— Hypoxia as a consequence of acute and chronic respiratory disease has been associated with muscle atrophy. This study investigated the sensitivity of oxidative and glycolytic muscles to hypoxia-induced muscle atrophy. Male mice were exposed to $8 \%$ normobaric oxygen for up to 21 days. Oxidative soleus and glycolytic extensor digitorum longus (EDL) muscles were isolated, weighed, and assayed for expression profiles of the ubiquitin-proteasome system (UPS), the autophagy-lysosome pathway (ALP), and glucocorticoid receptor (GR) and hypoxia-inducible factor- $1 \alpha(\mathrm{HIF} 1 \alpha)$ signaling. Fiber-type composition and the capillary network were investigated. Hypoxia-induced muscle atrophy was more prominent in the EDL than the soleus muscle. Although increased expression of HIF1 $\alpha$ target genes showed that both muscle types sensed hypoxia, their adaptive responses differed. Atrophy consistently involved a hypoxia-specific effect (i.e., not attributable to a hypoxia-mediated reduction of food intake) in the EDL only. Hypoxia-specific activation of the UPS and ALP and increased expression of the glucocorticoid receptor $(\mathrm{Gr})$ and its target genes were also mainly observed in the EDL. In the soleus, stimulation of gene expression of those pathways could be mimicked to a large extent by food restriction alone. Hypoxia increased the number of capillary contacts per fiber cross-sectional area in both muscles. In the EDL, this was due to type II fiber atrophy, whereas in the soleus the absolute number of capillary contacts increased. These responses represent two distinct modes to improve oxygen supply to muscle fibers, but may aggravate muscle atrophy in chronic obstructive pulmonary disease patients who have a predominance of type II fibers.

hypoxia; oxidative muscle; glycolytic muscle; protein-degradation pathways

WEIGHT LOSS AND MUSCLE ATROPHY are common features associated with respiratory diseases such as advanced chronic obstructive pulmonary disease (COPD) $(9,35,57)$, acute exacerbations of COPD (29), idiopathic pulmonary arterial hypertension (1), and acute respiratory distress syndrome (ARDS) (21). Loss of muscle mass is a strong predictor of mortality and significantly increases disease burden $(20,35,57)$. Hypoxia is well-known for its negative effect on muscle mass (5). Episodes of both acute and chronic hypoxia are hallmarks of the above-mentioned respiratory disorders (51); therefore, under-

Address for reprint requests and other correspondence: S. E. Köhler, Dept. of Anatomy and Embryology, NUTRIM School for Nutrition, Toxicology and Metabolism, Maastricht Univ. Medical Center+, PO Box 616, 6200 MD, Maastricht, The Netherlands (e-mail: leo.koehler@maastrichtuniversity.nl). standing the mechanisms by which hypoxia induces muscle atrophy may benefit disease management. Interestingly, muscle atrophy in advanced COPD patients is characterized by a reduction of the muscle fiber cross-sectional area (FCSA) and particularly affects the glycolytic type IIX and IIA/IIX hybrid fibers $(16,40)$. Moreover, a fiber-type shift with a decrease of type I (slow, oxidative) and an increase of type II fibers (fast, glycolytic) $(17,24,40,44)$ as well as a reduced capillarity (12) are observed, potentially rendering these patients even more vulnerable to hypoxia-induced muscle atrophy. Differential sensitivity of glycolytic and oxidative muscle to atrophy stimuli other than hypoxia has previously been observed in animal models $(34,37,48)$. To disentangle which muscle (fiber) types are most sensitive to hypoxia-induced muscle atrophy, we analyzed the effects of severe, acute, and chronic hypoxia on muscle mass and capillarity on the soleus, as a typical example of an oxidative muscle, and the extensor digitorum longus (EDL), as representative for a glycolytic muscle in mice (8). As oxidative fibers show higher oxygen consumption, we hypothesized that oxidative muscle fibers are less resistant to hypoxiainduced muscle atrophy than glycolytic muscle fibers. To test our hypothesis, mice were exposed to severe hypoxia for either 4 (acute) or up to 21 days (chronic) and compared with control mice kept under normoxic conditions. Since we have previously demonstrated a hypoxia-induced reduction of food intake (10), we also included a pair-fed control group in our experimental design. Muscle atrophy and gene expression profiles of relevant catabolic pathways were determined (Table 1). In addition, muscle capillarity was assessed. Our study shows that both oxidative and glycolytic muscles show structural adaptations to hypoxia that result in a reduced FCSA per capillary contact, and that hypoxia-induced atrophy mainly affects glycolytic fibers.

\section{MATERIALS AND METHODS}

Animals and tissue collection. Twelve-week-old C57BL/6J male mice (Charles River Laboratories International, Wilmington, MA) $(n=48)$ were randomly divided into three groups: normoxia $(\mathrm{N})$, normoxic animals pair fed to hypoxic animals (PF), and normobaric hypoxia $(\mathrm{H})$. Oxygen levels in the $\mathrm{H}$ group were reduced in a stepwise manner from ambient levels to $12 \%$ on day 1 , to $10 \%$ on day 2 , and finally to $8 \%$ on day 3 , and maintained at $8 \%$ for the remainder of the experiment. Of each group, eight mice were killed on day 4 ("acute" hypoxia) and another eight on day 21 ("chronic" hypoxia). The soleus and the EDL muscles were isolated and frozen for immunohistochemical analysis and RNA extraction. Tissue weights were corrected for starting body weight. Procedures are described in more detail in Ref. 10. Briefly, at the start of the experiments, four mice were placed in 
Table 1. Pathways and marker genes tested in this study

\begin{tabular}{lcc}
\hline \multicolumn{1}{c}{ Gene } & \multicolumn{1}{c}{ Function } & References \\
\hline & Ubiquitin 26S-proteasome system (UPS) & \\
Murf1 (Trim63) & E3 ubiquitin protein ligase & $(14)$ \\
Atrogin1 (Fbxo32) & E3 ubiquitin protein ligase & $(14,15)$ \\
Nedd4 & E3 ubiquitin protein ligase & $(27)$ \\
& Autophagy-lysosome pathway (ALP) & \\
Bnip3 & Regulation autophagy/mitophagy \\
Map1lc3B & Regulation autophagy/mitophagy & $(2)$ \\
Atg5 (Apg5) & E3 ubiquitin protein ligase & $(37)$ \\
& Glucocorticoid receptor (GR) signaling & \\
Glul & Ammonia and glutamine metabolism & $(36)$ \\
Msth & Inhibitor of myogenesis & $(33)$ \\
& Transcription factor, upregulates Murf1, \\
& Atrogin1, negative modulation of & \\
& myofiber size & \\
\hline
\end{tabular}

each cage. Mice and food were weighed daily. The food intake per day is an average from four mice. The pair-fed group started 1 day later than the hypoxic group and received the amount of food consumed by the hypoxic group the day before. Feeding always took place between 15:00 and 16:00 h. Body weight and food intake per day are shown in Ref. 10. All experimental protocols were submitted to and approved by The Committee for Animal Care and Use of Maastricht University.

$R T-q P C R$. RNA was isolated using TRI Reagent (Sigma-Aldrich Chemie, Zwijndrecht, The Netherlands). cDNA synthesis was performed with random hexamer primers by using the Transcriptor First Strand cDNA Synthesis Kit (Roche Nederland, Woerden, The Netherlands). Real-time quantitative PCR was performed in the iQ5 thermal cycler (Bio-Rad, Hercules, CA), using the qPCR SyBr Green Fluorescein Mix (Abgene, Epsom, UK) with intron-spanning primers (Table 2). mRNA expression was normalized to 18S rRNA.

Determination of FCSA and fiber-type composition. Seven micrometer cryosections were cut from the central region of each muscle and stained with antibodies against laminin (L9393, Sigma-Aldrich Chemie) to visualize fiber circumferences. To discriminate individual fiber types, the following stainings were carried out simultaneously using antibodies against the respective myosin heavy chain (MyHC) isotypes: MyHC-IIA [333-7H1, gift from A.F.M. Moorman (6)] and MyHC-I [A4.840, Developmental Studies Hybridoma Bank (DSHB)] for soleus tissue sections, and MyHC-IIA with MyHC-IIB (BF-F3, DSHB) for EDL sections. The unstained muscle fibers were considered to be composed of the remaining fiber types. FCSA and fiber types were analyzed with the LUCIA 4.81 imaging software package (Nikon).

Determination of capillary density. Capillaries were stained with anti-CD31 (PECAM1) antibody (557355, BD Biosciences) in combination with anti-laminin and anti-MyHC-IIB for EDL or anti-MyHC-I for soleus analysis, respectively. Analyses were performed using the Lucia 4.81 imaging software package (Nikon). Capillary density (CD) represents the number of capillary transections per square millimeter of a section. The capillary perimeter $(\mathrm{CP})(\mu \mathrm{m})$ was determined from the outline of the CD31 staining. Capillary contacts (CC) represent the number of capillary transections in direct contact (pixel to pixel) with a muscle fiber (distance $<2.2 \mu \mathrm{m}$, corresponding to the dimension of 2 pixels). The density of capillary contacts (CCD) represents the number of capillary contacts per square millimeter of a section. FCSA/capillary contact was calculated by dividing the average FCSA of one fiber-type with the average $\mathrm{CC}$ per picture. The interstitial space was determined on histologic sections by using the ImageJ software. The interstitial space was defined as the remaining surface area after subtraction of all surface area covered by muscle fibers, by endo- and perimysium (laminin staining), by capillaries and larger blood vessels (CD31-staining), and nerves (perineurium detected by laminin staining).

Western blotting. Soleus and EDL muscle tissue was lysed in presence of phosphatase and protease inhibitors. Proteins were separated using gradient polyacrylamide gels and transferred to a nitrocellulose transfer membrane by electroblotting. The membrane was stained with Ponceau S solution to measure total protein loaded and subsequently blocked with nonfat dried milk, before incubating overnight with primary antibody (Table 3). Horse peroxidase-labeled secondary antibody was used in combination with chemiluminescence to visualize the protein bands. Bands were quantified and corrected for total amount of protein loaded, based on the Ponceau S staining.

Statistics. Data are shown as means \pm SE. Comparisons were computed with SPSS version 15 (SPSS, IL). Statistical significance was tested by ANOVA. The type of post hoc analysis was based on data variance (Levene's test), with the Tukey test for data with equal variance, and the Games-Howell test for all other data. Statistical significance of basal (normoxic groups) differences between muscles was assessed using the Student's $t$-test. A $P$ value of $<0.05$ was considered to be statistically significant, and a $P$ value of $0.05 \leq P \leq$ 0.1 as indicating a trend.

\section{RESULTS}

Hypoxia-specific decrease of glycolytic muscle mass. Exposure to hypoxia affects food intake as we have shown previously (see Fig. 2 in Ref. 10). In our model, hypoxia-mediated decrease in food intake was maximal after 4 days of hypoxia

Table 2. Sequences of primers used for RT-qPCR to assess expression of the indicated genes

\begin{tabular}{|c|c|c|c|}
\hline Gene & NCBI & Forward Primer $\left(5^{\prime}\right.$ to $\left.3^{\prime}\right)$ & Reverse Primer $\left(5^{\prime}\right.$ to $\left.3^{\prime}\right)$ \\
\hline $18 S$ & NR_003278.1 & AGTTAGCATGCCAGAGTCTGC & TGCATGGCCGTTCTTAGTTG \\
\hline Murf1 (Trim63) & NM_00103904 & TGTCTGGAGGTCGTTTCCG & CTCGTCTTCGTGTTCCTTGC \\
\hline Atrogin1 (Fbxo32) & NM_026346.2 & ACCGGCTACTGTGGAAGAGA & CCTTCCAGGAGAGAATGTGG \\
\hline Nedd4 & NM_010890.3 & GCTGCCAAGAGCACACACCTG & CAACGCCATCAAAGCCCTGT \\
\hline Bnip3 & NM_009760.4 & CCATGTCGCAGAGCGGG & GACGGAGGCTGGAACGC \\
\hline Map1lc3B & NM_026160.4 & GAGCAGCACCCCACCAAGAT & CGTGGTCAGGCACCAGGAA \\
\hline $\operatorname{Atg} 5$ (Apg5) & NM_053069.5 & TTGAATATGAAGGCACACCCC & CTCTTGAAATGTACTGTGATGTTCCAA \\
\hline$G r$ & NM_001873 & CGCCAAGTGATTGCCGC & TGTAGAAGGGTCATTTGGTCATCCA \\
\hline Glul & NM_008131.3 & GGCCATGCGGGAGGAGA & GGTGCCTCTTGCTCAGTTTGTCA \\
\hline Mstn & NM_010834.2 & GGCCATGATCTTGCTGTAACCT & CGGCAGCACCGGGATT \\
\hline Klfl5 & NM_023184.3 & TGCAGCAAGATGTACACCAAGAG & ATCGCCGGTGCCTTGAC \\
\hline Glut1 & NM_011400.3 & TGACCATCGCCCTGGCCT & GGACCAGGGCCTACTTCAAAG \\
\hline Vegfa & NM_009505.4 & CTGTACCTCCACCATGCCAAGT & TCGCTGGTAGACATCCATGAACT \\
\hline $\mathrm{Ca9}$ & NM_139305.2 & CAGGAGGCCTGGCAGTTTT & TTCTTCCAAATGGGACAGCAA \\
\hline
\end{tabular}


Table 3. Antibodies used for Western blotting

\begin{tabular}{lcl}
\hline \hline \multicolumn{1}{c}{ Target } & Product number & \multicolumn{1}{c}{ Company } \\
\hline LC3B & 2775 & Cell Signaling \\
Polyubiquitin conjugates & BML-PW8805 & ENZO Life Sciences \\
GR S211 & 4161 & Cell Signaling \\
GR & 3660 & Cell Signaling \\
\hline
\end{tabular}

and then increased to stabilize from day 11 onward, albeit at a lower level than in normoxic animals (9). We, therefore, included an extra group of mice, which were kept under normoxic conditions and pair fed to the mice exposed to hypoxia. This allowed us to separate effects of hypoxia into a hypoxia-specific component (independent of food intake) and a component that can be mimicked by a reduction in food intake. Accordingly, hypoxia-specific responses refer to comparisons between pair-fed (PF) groups and mice exposed to hypoxia $(\mathrm{H})$, whereas the response to hypoxic conditions refers to the comparison between normoxic control (C) and hypoxic mice and include the combined effects of hypoxia and reduced food intake. Compared with the pair-fed group, the EDL muscle of hypoxic mice already showed significant weight loss at 4 days, which was progressive during the next 2.5 wk (Fig. 1A). The soleus, on the other hand, was less sensitive to hypoxia but still showed a decrease to $93 \%$ after 21 days compared with normoxic animals (H vs. N: $P<0.05$; Fig. $1 B$ ), but did not differ from the pair-fed mice, who showed a comparable trend (H vs. PF: $P=0.10$ ). These data reveal a hypoxia-specific reduction of tissue mass in the glycolytic EDL muscle only, whereas the weight reduction of the soleus was slower and partially mimicked by the reduction in food intake (N vs. PF: $P=0.10)$.

Hypoxia reduces the FCSA in the EDL only. Transverse sections of the EDL (Fig. 2A) and the soleus muscles (Fig. 2B) were stained with antibodies against myosin heavy chains and laminin to identify individual fiber types (Fig. 2, $A$ and $B$, left) and their contours (Fig. 2, $A$ and $B$, right). In the EDL a small but significant reduction of the number of type IIB fibers was observed after 21 days (H vs. PF: $P<0.01$ ) (Fig. $2 C$ ), whereas in the soleus, the numbers of individual fibers were not changed under any of the experimental conditions (Fig. 2D). In the EDL, a significant reduction of the size of all fibers (Total) was already observed after 4 days of hypoxia, was progressive, and had a clear hypoxia-specific component (PF vs. H: $P<$ $0.05)$. Analysis of the FCSA of individual fibers revealed that the changes were mostly due to a decrease in type IIB fibers and a smaller decrease in type IIA fibers, whereas type IIX fibers were not affected (Fig. $3 A$ ). In the soleus, the mean FCSA of individual fiber types and, accordingly, of all fiber types (Total) was not significantly changed under any of the experimental conditions (Fig. 4A). Further analysis of the size distribution of specific fibers of the EDL revealed a small shift with the disappearance of the largest IIB type and IIA type fibers. Small changes were already visible at day 4 (Fig. $3 C$ ) and were more pronounced at day 21 (Fig. 3D). In the soleus, we did not find this decrease in size for any of the fiber types throughout the experiment (Fig. 4, $B$ and $C$ ).

We did not observe a fiber-type shift after 4 or 21 days of hypoxia in either muscle. Since the cross-sectional area of the EDL is covered for $86 \%$ by the larger type IIB fibers with the remainder made up by the smaller type IIA and IIX fibers, respectively (Fig. $3 B$ ), the reduction in muscle weight during hypoxia was mainly due to atrophy of type IIB fibers. These data show that the type IIB fibers in the EDL are most sensitive to hypoxia.

Differential expression of HIFl $\alpha$ target genes in EDL and soleus. Previously, we demonstrated lowered $\mathrm{SaO}_{2}$ (saturation level of oxygen in hemoglobin) and $\mathrm{PaO}_{2}$ (partial pressure of oxygen in arterial blood) values in the blood of mice after acute ( 2 and 4 days) and chronic (21 days) exposure to hypoxia (10). To assess hypoxia-associated signaling, expression of the HIF1 $\alpha$-responsive target genes Glut1 (glucose transporter 1, Fig. 5A), Vegfa (vascular endothelial growth factor A, Fig. 5B), and $\mathrm{Ca} 9$ (carbonic anhydrase 9, Fig. 5C) was determined. Glutl expression was most sensitive to hypoxia and $\mathrm{Ca} 9$ least responsive. Basal expression levels of Glut1 and Vegfa were 1.4-fold higher in the soleus than the EDL, and $\mathrm{Ca} 9$ 3.1-fold higher in the EDL. Glut1 expression was induced in both muscles already at day $4(\sim 1.5$-fold, $\mathrm{H}$ vs. $\mathrm{N})$. In the soleus, the increased expression was independent of food intake and similar under acute and chronic hypoxia, whereas in the EDL, the increase at day 4 was partially accounted for by reduced
A

Fig. 1. Hypoxia-specific decrease of glycolytic but not oxidative muscle weights. Mice were exposed to normoxia or hypoxia, and one normoxic group was pair fed to the hypoxia group. Mice were killed at the indicated time points, and muscle weights were determined: extensor digitorum longus (EDL) $(A)$ and soleus $(B)$. Muscle weights were corrected for starting body weight and expressed as the percentage of the normoxic value for the corresponding time point. Significant differences between groups at a given time point: $* P<0.05, * * P \leq 0.01$, $* * * P \leq 0.001$ ( $n=6-8$ per group).

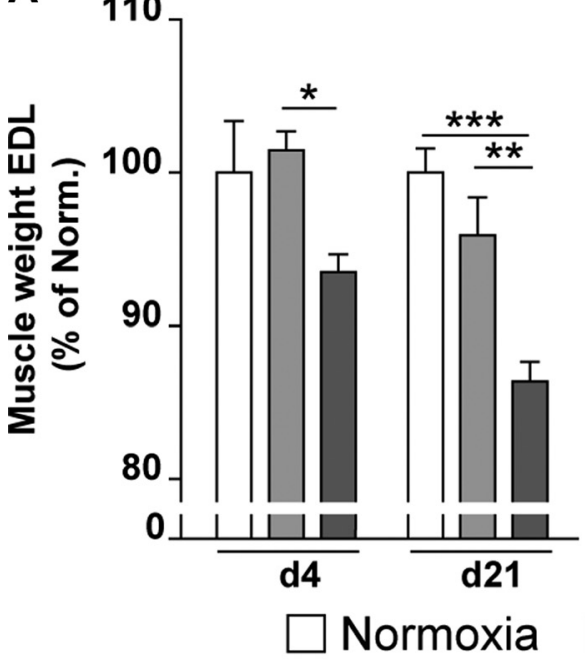

B

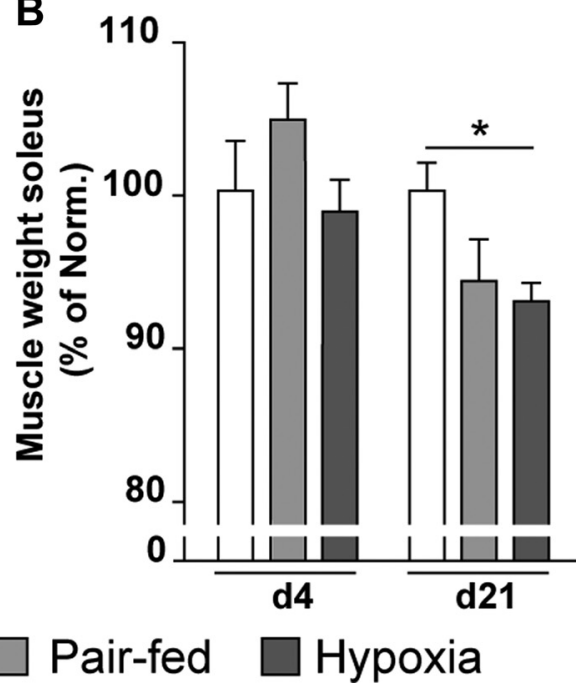


A
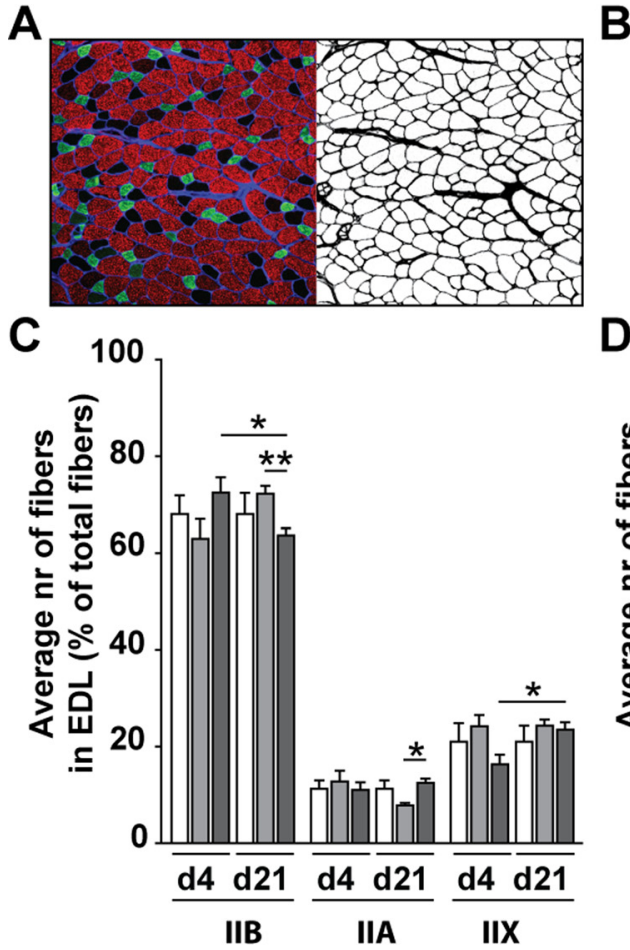

Normoxia
$B$

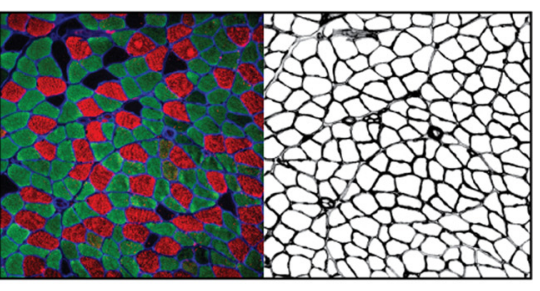

D

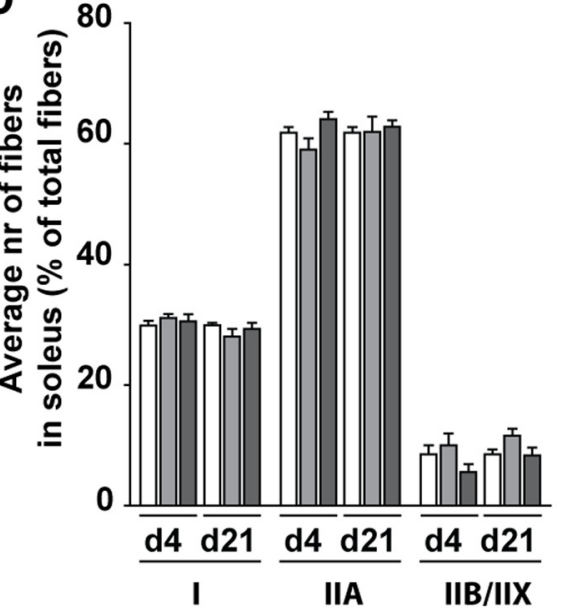

Fig. 2. Twenty-one days of hypoxia do not lead to a fiber-type shift. Muscle sections were analyzed histologically by using fluorescence-labeled antibodies. $A$, left: immunofluorescence staining of a cross section of the EDL muscle at 21 days with antibodies against MyHC-IIA (green), MyHC-IIB (red), and laminin (blue) to visualize fiber boundaries. Unstained fibers represent MyHC-IIX fibers (black). A, right: fiber boundaries and blood vessels of the same section visualized by anti-laminin staining. $B$, left: immunofluorescence staining of a cross section of the soleus muscle at 21 days with antibodies against MyHC-I (red), MyHC-IIA (green), and laminin (blue). Unstained fibers (black) represent MyHCIIX/IIB fibers. B, right: fiber boundaries and blood vessels of the same section visualized by antilaminin staining. $C$ : average number of fibers per fiber-type expressed as percentage of total fibers in the EDL muscle at days 4 and 21 in the three groups of mice. $D$ : average number of fibers per fiber-type expressed as percentage of total fibers in the soleus. Significant differences between groups at a given time point: $* P<0.05, * * * P \leq 0.001(n=6-8$ per group). food intake. After 21 days, however, Glutl expression was further increased and hypoxia specific in the EDL as well. $V e g f a$ showed a hypoxia-specific increase in both muscles only after 21 days, with a trend (PF vs. H, $P=0.09$ ) already visible in the soleus after 4 days. A significant, hypoxia-specific increase of $\mathrm{Ca} 9$ was only found in the EDL after 21 days. Together, these data suggest a hypoxic response in both muscles, with a stronger initial response in the oxidative soleus muscle and a stronger late response in the EDL.

Gene expression of ubiquitin ligases shows differential sensitivity to hypoxia. To assess whether oxidative and glycolytic muscles showed differential activation of UPS-mediated protein degradation pathways, we measured the expression of the E3 ubiquitin ligases Murf1, Atrogin-1, and Nedd4 (Fig. 6, A-C) and determined the amount of polyubiquitin conjugates in muscle (Fig. 6, D and E). Basal expression of Atrogin-1 and Murf1 was comparable in EDL and soleus, and both muscles responded with increased expression under hypoxia, but the response in the EDL was larger for both genes and faster for Atrogin-1. Increased expression of Murfl could be mimicked by a reduction in food intake in both muscles, whereas the increased Atrogin-1 expression showed a clear hypoxia-specific component, but only in the EDL. Basal Nedd4 expression was almost 5 times higher in the EDL than the soleus and was further increased in a hypoxia-specific manner in the EDL. These data show that Nedd4 was most sensitive to hypoxiaspecific induction, whereas induction of both Murfl and Atrogin-1 also showed a response to the decreased food intake. The increased gene expression of ubiquitin ligases was not reflected in an increase of polyubiquitin conjugates in either the EDL or soleus.

Effects of hypoxia on the autophagy-lysosome pathway. To investigate autophagy-lysosome pathway (ALP) mediated pro- tein degradation, the expression of Mapllc3b, Bnip3, and Atg5 was measured (Fig. 7, $A-C$ ), whereas LC3B activation was determined by quantifying lipidated LC3B-II (Fig. 7, $D$ and $E$ ). Basal expression of Mapllc3b was similar in EDL and soleus, and both muscles showed increased expression after acute and chronic hypoxia. In the soleus, this increase depended on food restriction, whereas the more pronounced increase in the EDL contained a hypoxia-specific element. Basal expression of Bnip3 was 2-fold higher in the soleus, but both muscles showed a hypoxia-specific upregulation. In the EDL, this was partly due to the hypoxia-mediated reduction in food intake. Basal Atg5 expression was slightly higher in the soleus, but hypoxia-specific increased expression was only observed in the EDL. Induction of Atg5 expression was hypoxia-specific, whereas Map $1 l c 3 b$ and Bnip3 showed also a response to the lowered food intake. LC3B protein concentration was $\sim 2$-fold and that of the active lapidated form, LC3B-II, even 3.2-fold higher in the soleus than the EDL. Hypoxia led to a hypoxiaspecific reduction of LC3B-II in both soleus and EDL in the acute phase. In the chronic phase the reduction also showed a food intake-dependent component.

Hypoxia-induced glucocorticoid signaling is more prominent in the glycolytic EDL. To assess whether glucocorticoid signaling was involved in hypoxia-mediated muscle atrophy, we analyzed GR content and phosphorylation at S211 (Figs. 8, $A-C$ ) and mRNA expression (Fig. 8D) and that of its target genes Krüppel-like factor 15 (Klfl5), myostatin (Mstn), and glutamine synthetase $(G l u l)$ (Figs. 8, E-G). Except for a temporary hypoxia-specific decrease of phosphorylated GR in the EDL, changes in GR content and phosphorylation at S211 were small. Basal mRNA concentrations of $\mathrm{Gr}$ were comparable in both muscles and showed a hypoxia-specific increase in expression within 4 days, which was, however, only sus- 
Fig. 3. Hypoxia-specific decrease of the fiber crosssectional area (FCSA) in the glycolytic EDL. Muscle sections were analyzed histologically using fluorescence-labeled antibodies. A: mean FCSA of all fibers (Total) and individually stained fibers type IIB and IIA, and unstained fibers (type IIX) of the EDL muscle. B: fiber distribution in the EDL as percentage of the total surface area. $C$ : FCSA distribution of the EDL muscle per fiber-type on day 4. $D$ : FCSA distribution of the EDL muscle per fibertype on day 21; no significance indicated. Panels at top: type IIB fibers; panels at middle: type IIA fibers; panels at bottom: type IIX fibers. Significant differences between groups at a given time point: $* P<0.05, * * P \leq 0.01, * * * P \leq 0.001(n=6-8$ per group).
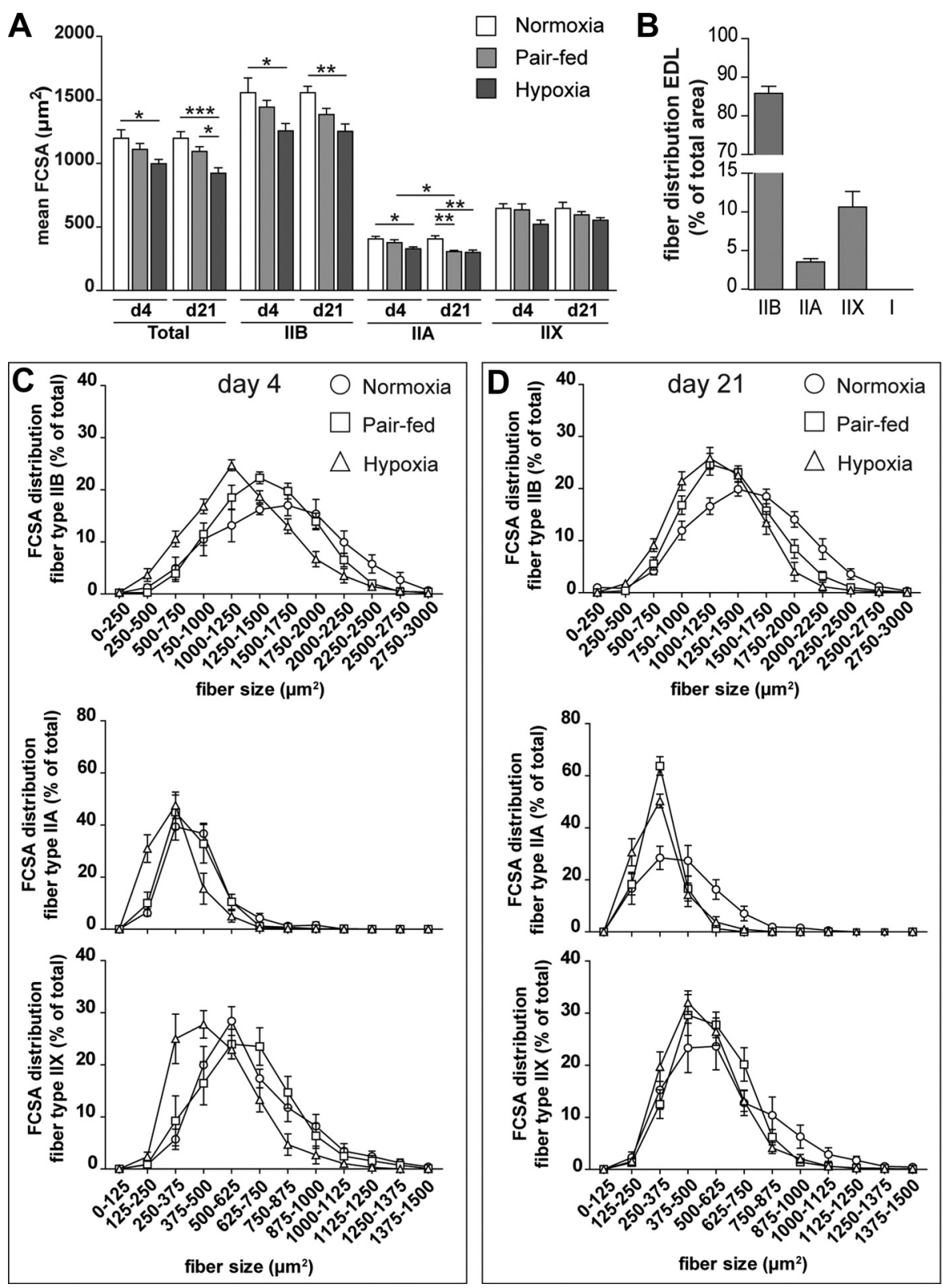

tained in the EDL. Basal expression of the GR target gene Klf15 was comparable in both muscles, and both responded with increased expression to acute and chronic hypoxia. In the soleus, however, this response was dependent on the reduced food intake, whereas in the EDL it was partially hypoxiaspecific (Fig. 8E). Basal expression of Mstn was 27 -fold higher in the EDL than the soleus (Fig. $8 F$ ). Whereas expression was insensitive to hypoxia in the soleus, expression was increased in the EDL after 21 days, which was partially accounted for by reduced food intake. Basal expression of Glul was 2.3-fold higher in the EDL than the soleus (Fig. 8G). This expression was increased almost 2-fold in a hypoxia-specific manner at day 21 in the EDL, whereas only a trend ( $\mathrm{H}$ vs. $\mathrm{N}, P=0.06$ ) toward an increased expression was seen in the soleus. To summarize, expression of $G r$ and $G l u l$ were upregulated in a hypoxia-specific manner, whereas Klf15 was regulated by food intake. The glycolytic EDL muscle was more sensitive to hypoxia-specific induction of glucocorticoid signaling than the soleus.

Hypoxia results in muscle-specific adaptations of the capillary network. Hypoxia triggers angiogenesis $(26,28,54,56)$. We used CD31 staining to identify and quantify capillaries in the EDL and the soleus (Figs. 9, $A$ and $B$ ). The increased Vegfa expression suggests adaptations of the capillary network within the muscles. Under normoxic conditions, the CD in the EDL (Fig. 9C) was significantly lower than in the soleus (807 vs. 1,079 capillaries $/ \mathrm{mm}^{2}$, respectively). The number of capillaries per square millimeter (Fig. $9 \mathrm{C}$ ) and of $\mathrm{CC}$ per square millimeter (Fig. 9D) were both 1.4-fold higher in the soleus than the EDL. Capillaries were also slightly larger in the soleus (Fig. $9 E$ ), and a hypoxia-specific reduction of the interstitial space between fibers was found in the soleus after 21 days (Fig. 9G). Together, these changes explain the more frequent $\mathrm{CC}$ in this muscle, resulting in a smaller FCSA per capillary contact (Fig. 

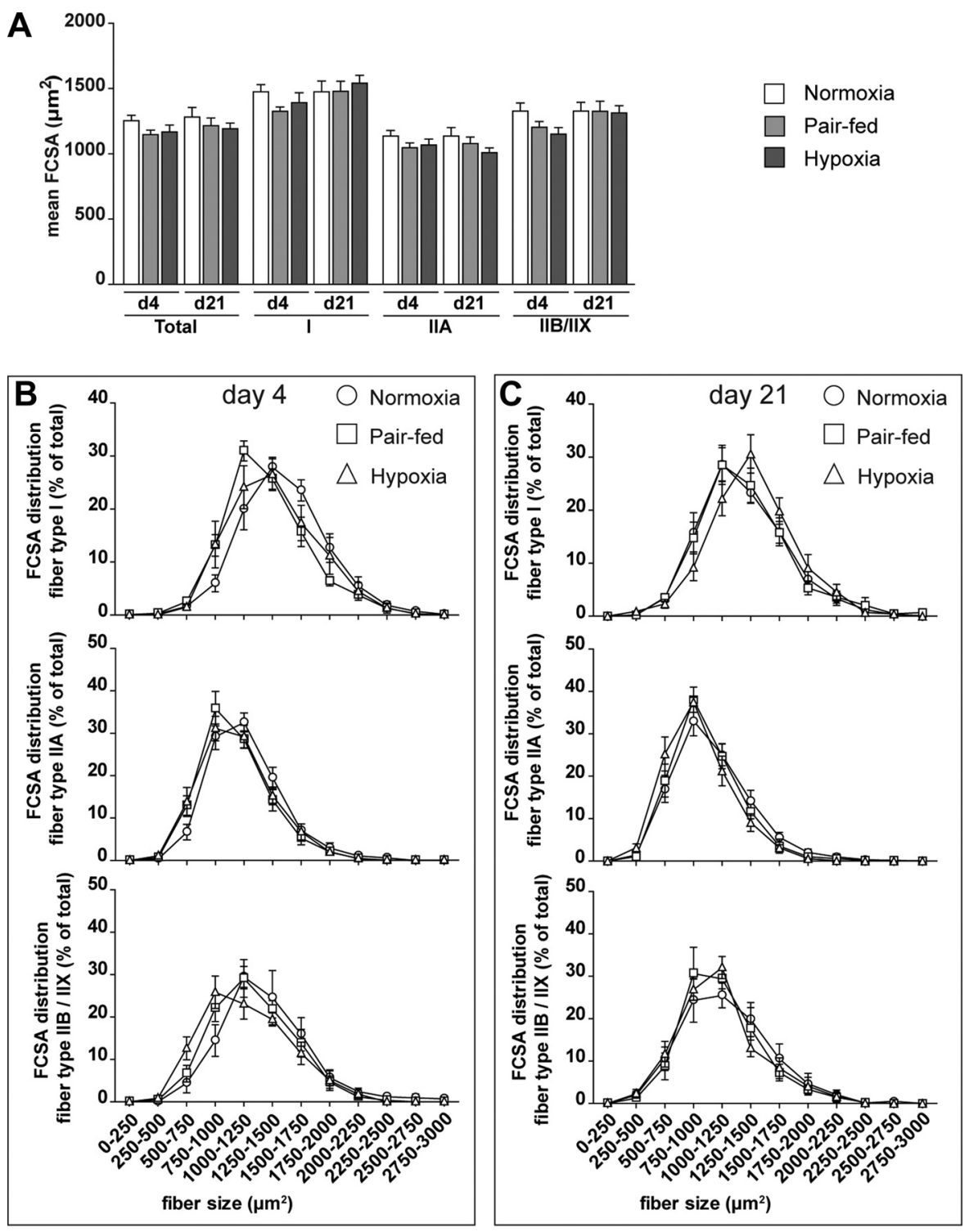

Fig. 4. The oxidative soleus muscle shows no changes in fiber size distribution. Muscle sections were analyzed histologically using fluorescence-labeled antibodies. A: mean FCSA of all fibers (Total) and individually stained fibers (type IIB/IIX) of the soleus muscle. $B$ : FCSA distribution of the soleus muscle per fiber-type on day 4. C: FCSA distribution of the soleus muscle per fiber-type on day 21; no significance indicated. Panels at top: type I fibers; panels at middle: type IIA fibers; panels at bottom: type IIB/X fibers.

$9 F$ ), which may facilitate a better blood supply to the muscle fibers of the soleus. In the EDL, a hypoxia-specific increase in $\mathrm{CD}$ was observed, but no change in the $\mathrm{CC}$ per unit surface. In both muscles, hypoxia, therefore, caused a decrease of the FSCA per capillary contact and thereby a better blood supply of the fibers. The effects of reduced food intake on CD, contacts, and perimeter were small.

\section{DISCUSSION}

In this study we investigated the atrophy responses of a mainly oxidative muscle, the soleus, and a predominantly glycolytic muscle, the EDL. The effects of hypoxia on muscle consisted of a food intake-dependent effect and a hypoxiaspecific effect (independent of the hypoxia-mediated reduction in food intake). The main findings were that 1) both muscles adapted to chronic hypoxia with a similar result, namely a reduction of the FCSA per capillary contact, but achieved this via a different path, that is, a decrease of FCSA in the EDL and an increase of $\mathrm{CC}$ in the soleus; 2) the increased sensitivity of the EDL to hypoxia was reflected in increased hypoxia-specific expression of genes of the UPS and the ALP, whereas in the soleus this response was smaller and showed a stronger dependence on food intake; 3) expression of $G r$ mRNA and target genes of GR was hypoxia-specific in the EDL and stronger than in the soleus; and 4) the ubiquitin ligase Nedd4 and the autophagy-related factor Atg5 are upregulated in a hypoxiaspecific manner.

In the present study, we showed a rapid decrease of muscle mass and FCSA in the glycolytic EDL muscle, but not the oxidative soleus muscle in response to normobaric hypoxia. After 3 wk of hypoxia, muscle atrophy was still most prominent in the EDL, suggesting that loss of glycolytic muscle mass is a feature of chronic hypoxia. The reduction in muscle mass was reflected in a reduction of the FCSA of the predominant type IIB muscle fibers in the EDL. Rats that were exposed for $10 \mathrm{wk}$ to hypobaric hypoxia also showed a selective reduction of the FCSA of the glycolytic EDL (23). A consistent finding in COPD patients is a fiber-type redistribution from oxidative type I fibers toward more glycolytic type II fibers $(17,18,24$, $40,44)$, which may already be present in mild to moderate 

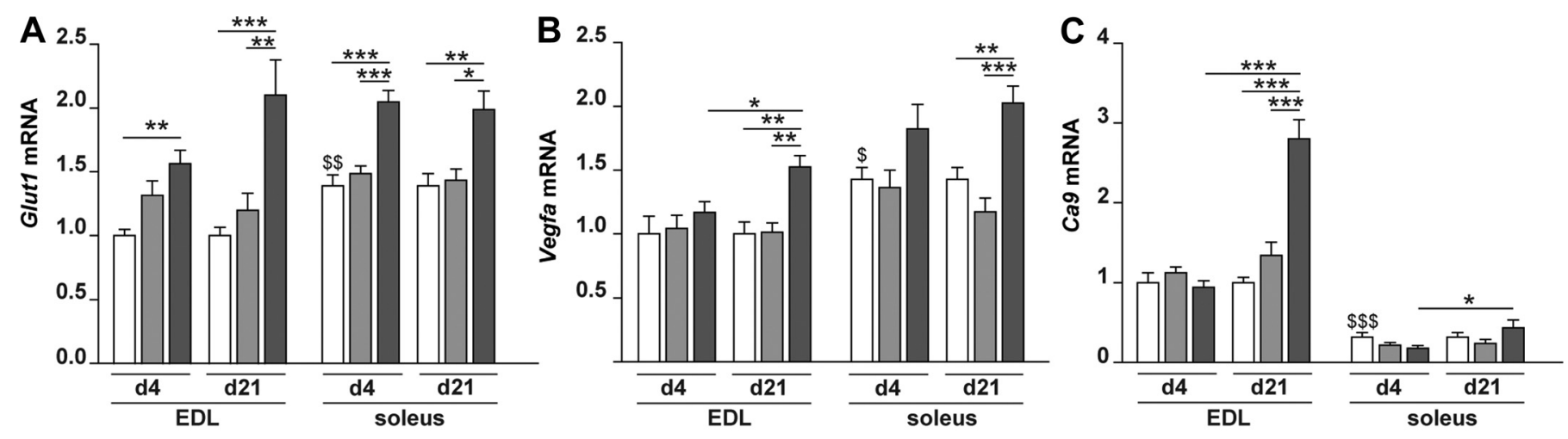

$\square$ Normoxia $\square$ Pair-fed $\square$ Hypoxia

Fig. 5. Differential expression of HIF1 $\alpha$ target genes. mRNA expression of HIF1 $\alpha$ target genes was determined: Glut1 (A), Vegfa (B), and Ca9 (C). mRNA concentration was corrected for 18S RNA concentration and normalized to the normoxic value of the EDL at day 4. Significant differences of normoxia (basal) values between muscles are indicated with $\$$; significant differences between groups at a given time point: */\$P<0.05, **/\$\$P $\leq 0.01$, ***/\$\$ $\$ P \leq 0.001(n=$ $6-8$ per group).

disease (53). We previously showed selective atrophy of type II fibers in COPD patients relative to age-matched control subjects (16). The findings of the present study suggest that this may be due to an unfortunate series of events, initiated by a shift toward type II fibers, that is, toward a muscle phenotype that subsequently renders COPD patients more sensitive to disease-related episodes of hypoxia and cachexia in advanced disease.
Activation of GR signaling in muscle induces atrophy (49, 55). Sensitivity of fast-twitch muscle fibers, like the EDL, to glucocorticoid-induced atrophy was previously demonstrated in rats (46). Here, we show that basal $G r$ mRNA concentrations were the same in both muscles, but that acute and chronic hypoxia upregulated $G r$ expression only in the glycolytic EDL muscle. Interestingly, GR protein levels did not respond accordingly. However, GR recycling and degradation are tightly
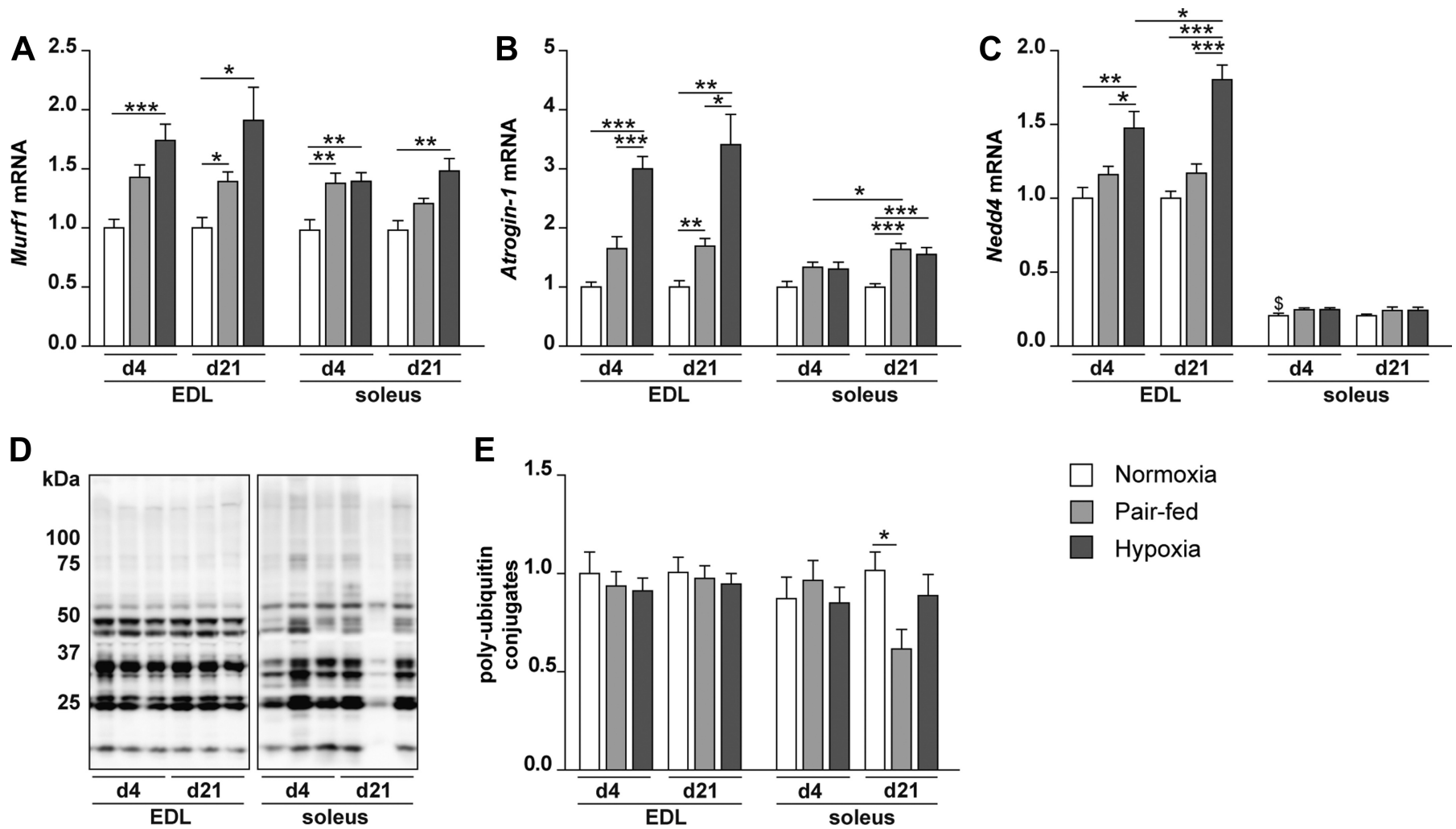

E

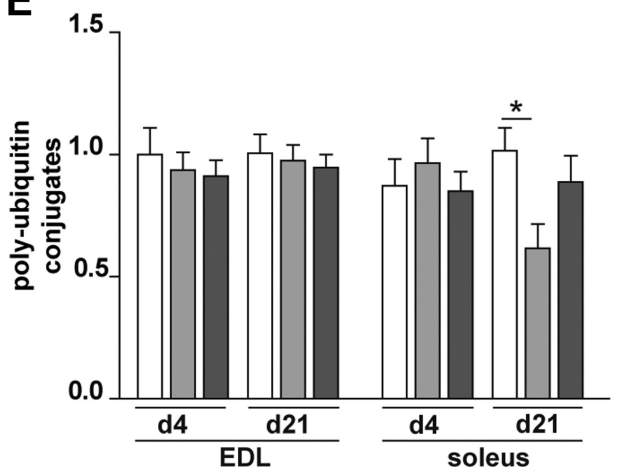

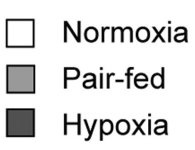

Fig. 6. Hypoxia affects the expression of genes of the ubiquitin-proteasome system (UPS), predominantly in the glycolytic EDL muscle, but does not lead to accumulation of polyubiquitin conjugates. mRNA expression of genes belonging to the UPS: Murf1 (A), Atrogin-1 (B), and Nedd4 (C); mRNA concentration was corrected for 18S RNA and normalized to the normoxic value of the EDL at day 4. D: representative Western blots of polyubiquitin conjugates in protein extracts of EDL (left) and soleus muscles (right) from mice of all three experimental groups at 4 and 21 days. E: total polyubiquitin conjugates per condition. Ponceau S staining was used to correct for protein loading. Significant differences of normoxia (basal) values between muscles are indicated with $\$$; significant differences between groups at a given time point: $* / \$ P<0.05, * * P \leq 0.01, * * * P \leq 0.001$ ( $n=6-8$ per group). 

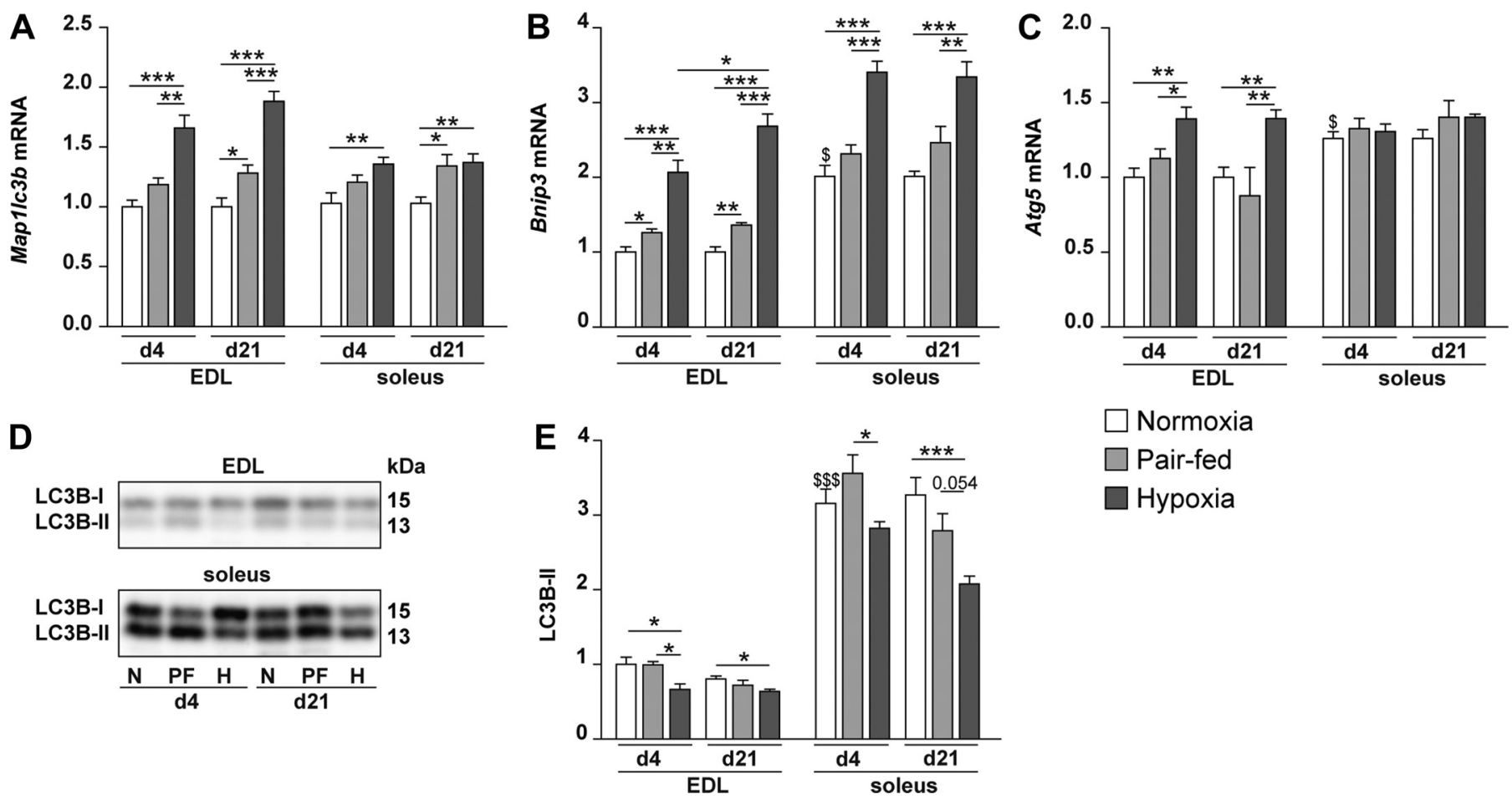

Fig. 7. Hypoxia-specific induction of genes of the autophagy-lysosome pathway (ALP) in the EDL. mRNA expression of genes belonging to the ALP was measured: Map1lc3b (A), Bnip3 (B), and Atg5 (C). mRNA concentration was corrected for 18S RNA and normalized to the normoxic value of the EDL at day 4. D: representative Western blots of LC3B protein in the EDL (panel at top) and soleus muscles (panel at bottom) from mice of all three experimental groups at 4 and 21 days. E: LC3B-II concentration normalized to the normoxic value of the EDL at day 4. Ponceau S staining was used to correct for protein loading. Significant differences of normoxia (basal) values between muscles are indicated with $\$$; significant differences between groups at a given time point: $* / \$ P<$ $0.05, * * P \leq 0.01 * * * / \$ \$ P \leq 0.001(n=6-8$ per group $)$.

controlled following GR activation and may have been affected by hypoxia (52). It was shown previously that severe hypoxia potentiates glucocorticoid activity through the induction of the glucocorticoid receptor in human kidney cells and that HIF1 $\alpha$ is responsible for at least part of this induction (30). The observed predominant GR response to hypoxia in the EDL is in line with a higher sensitivity of this glycolytic muscle to glucocorticoids (31). Klfl5 is a GR-sensitive gene required for amino acid degradation to provide carbohydrate backbones for gluconeogenesis under fasting conditions (19). In line with this function, increased expression was observed in soleus and EDL muscles in response to reduced food intake. KLF15, glutamine synthetase $(G l u l)$, and myostatin have been implicated in protein catabolism and inhibition of muscle growth, respectively $(22,50)$. The additional hypoxia-induced increase of their mRNAs in the EDL corresponds with the accentuated hypoxia-specific loss of mass of this muscle.

The observed hypoxia-induced skeletal muscle atrophy involves increased expression of genes of the UPS and ALPmediated protein degradation pathways (10). During UPSmediated protein degradation, proteins are labeled through the addition of ubiquitin chains by E3 ubiquitin ligases. The lack of accumulation of polyubiquitin conjugates indicates that proteasomal capacity is not limiting and ubiquitin homeostasis is not disturbed (42). Basal expression and induction by hypoxia-induced reduction of food intake of the E3 ubiquitin ligases Murfl and Atrogin-1 was not different between muscle types. Hypoxia-specific, food intake-independent increases in E3 ubiquitin ligase expression were only observed in the glycolytic EDL muscle. Interestingly, changes in Klf15 expression paralleled the response of Murfl and Atrogin-1, both downstream targets of KLF15 (50). The increased expression of Murfl and Atrogin-1 may be the consequence of an increased sensitivity of the EDL to corticosterone and GR signaling. Expression of the E3 ubiquitin ligase Nedd4 did not mimic the expression patterns of Murfl and Atrogin-1. This ligase is highly expressed in the glycolytic EDL muscle but not the oxidative soleus muscle. In addition, increased Nedd4 expression is dependent on hypoxia only and not on reduced food intake. Increased Nedd 4 expression was previously identified as a marker to distinguish muscle atrophy caused by reduced muscle tension from cachexia-induced atrophy (27). Our findings indicate that Nedd4 expression may also be a marker for hypoxia and hypoxia-induced atrophy in glycolytic muscle.

The elevated expression of Bnip3, Map1lc3b, and Atg5 in the hypoxic EDL suggested that the ALP is involved in hypoxia-specific atrophy of this muscle. In addition, expression of Bnip3, a hypoxia-inducible member of the Bcl-2 family and a regulator of cardiomyocyte mitophagy under hypoxic conditions (45), was increased in the oxidative soleus muscle by hypoxia, and this was independent of food intake. Bnip3 may therefore contribute to muscle adaptations other than atrophy, such as mitochondrial loss by mitophagy $(2,59)$. The increased hypoxia-specific expression of Maplc3b and Atg5 in the EDL together with the decreased concentration of LC3B-II may be interpreted as increased flux through the ALP (25). It has to be noted, however, that relations between LC3B-I and LC3B-II 
A

Fig. 8. Hypoxia-induced glucocorticoid signaling is more prominent in the glycolytic EDL muscle. Phosphorylation of GR at serine 211 was measured as an indication of its activation in the EDL and the soleus of mice exposed to one of the three experimental conditions [normoxia $(\mathrm{N})$, pair-fed $(\mathrm{PF})$, or (H) hypoxia] for 4 or 21 days. A: representative Western blots of total GR and phosphorylated GR. $B$ : GR S211. C: total GR. Ponceau S staining of Western blots was used to correct for protein loading. mRNA expression of $\mathrm{Gr}$ and its target genes was determined: $G r(D), K l f 15(E), \operatorname{Mstn}(F)$, and Glul $(G)$. mRNA concentration was corrected for 18S RNA and normalized to the normoxic value of the EDL at day 4. Significant differences of normoxia (basal) values between muscles are indicated with \$; significant differences between groups at a given time point: $* P<0.05, * * P \leq 0.01$ $* * * / \$ \$ P \leq 0.001$ ( $n=6-8$ per group).

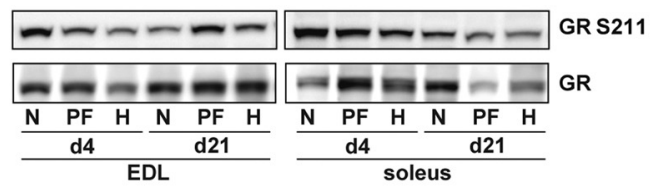

Normoxia $\square$ Pair-fed $\square$ Hypoxia

B

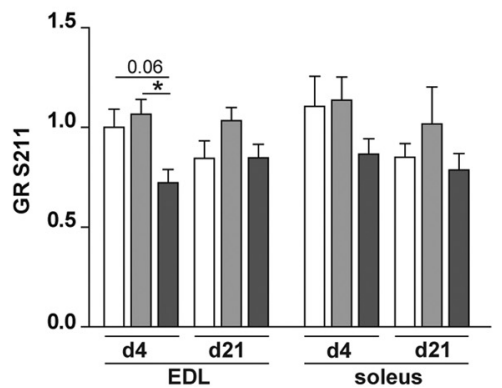

D

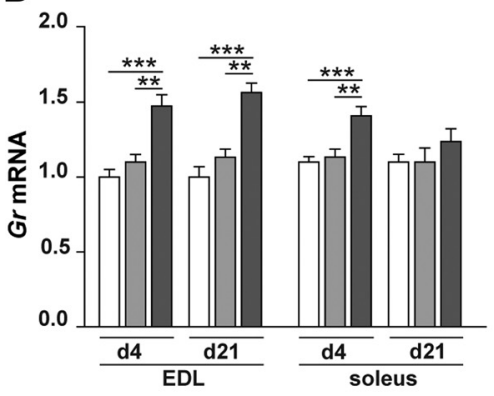

$\mathbf{F}$

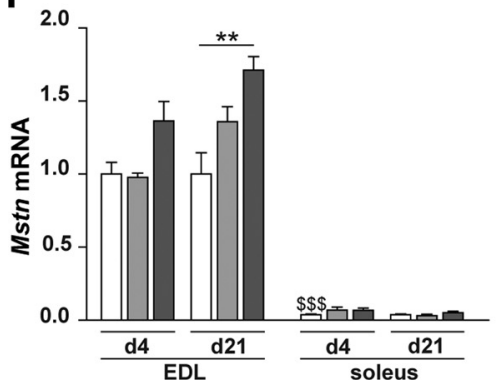

C

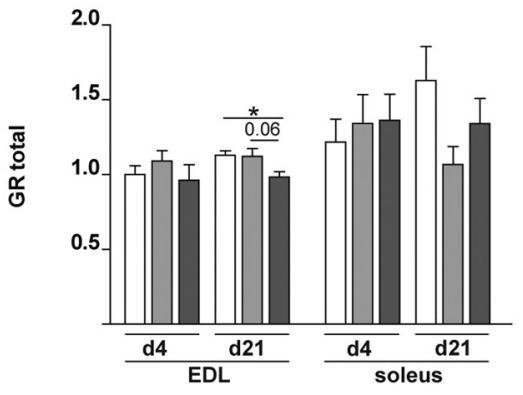

E

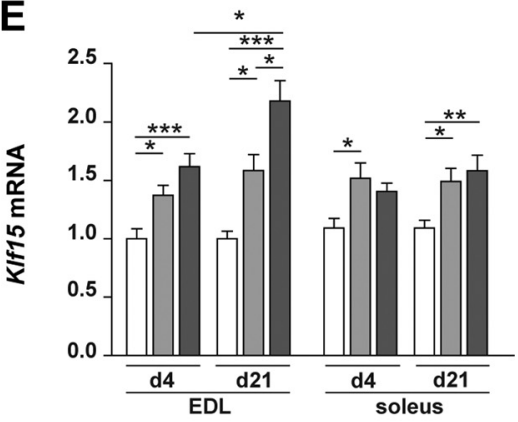

G

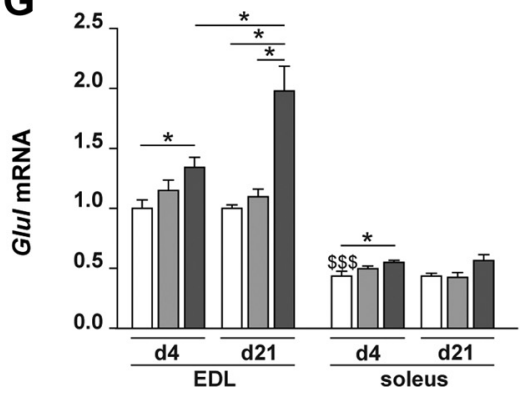

depend on the type of cell and the type of stress and cellspecific transcriptional regulation, rendering the interpretation of these data notoriously difficult (25). Although the main objective of this study was to characterize the different sensitivities of oxidative and glycolytic muscle toward hypoxia and underlying mechanisms, it seems worthwhile to note that the expression of Atg5, a crucial component of the autophagy machinery, is entirely dependent on hypoxia and independent of food intake, so that it qualifies, like Nedd4, as a marker for hypoxia-induced atrophy in glycolytic muscle.

Glycolytic muscles in mice have higher concentrations of HIF1 $\alpha$ protein and mRNA than oxidative muscles (32). HIF $1 \alpha$ activation can regulate the expression of its downstream targets Ca9, Vegfa, and Glut1, as well as Bnip3. Expression of Glutl and Vegfa increased in both muscles upon exposure to hypoxia, whereas $\mathrm{Ca} 9$ was only upregulated in the glycolytic EDL muscle and only after chronic exposure. This latter finding suggests a delayed response to hypoxia for this gene, although the exact function of $\mathrm{Ca} 9$ remains unclear. The early increase in glucose transporter 1 (Glut1) expression probably reflects the increased glucose uptake under hypoxia as shown by others (13).

Vascular endothelial growth factor (VEGF) is a potent angiogenic factor in hypoxic tissues (7). Basal Vegfa expression was higher in oxidative soleus than in glycolytic EDL muscle. This may relate to the higher CD in oxidative muscles, as expression of Vegfa in endothelial cells is 2-fold higher than in skeletal muscle cells (3). Chronic hypoxia resulted in a significantly increased expression of Vegfa in both muscles. The angiostatic effect of glucocorticoids has been explained by their inhibition of VEGF expression (41), which at least in vitro, is potentiated by hypoxia (30). It is, therefore, tempting to speculate that the effects of increased Vegfa expression were attenuated in glycolytic muscles like the EDL by their higher 

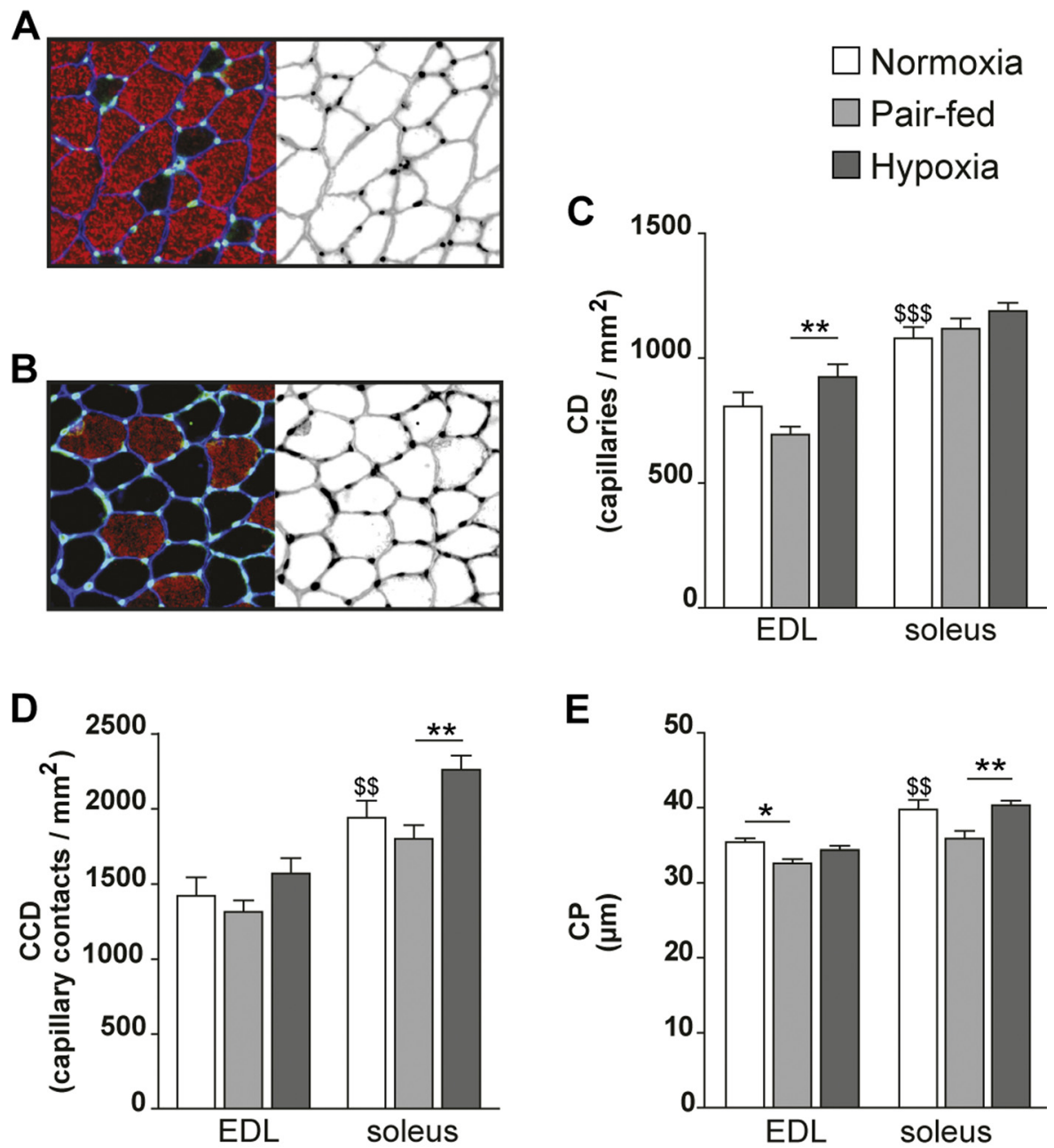

Fig. 9. Hypoxia results in muscle-specific adaptations of the capillary network and the interstitial space. Capillary staining with fluorescent antibodies was combined with fiber-type-specific staining to characterize the capillary network around fibers. Laminin staining was used to indicate fiber boundaries. Immunofluorescence staining of a cross section of the EDL with antibodies against CD31 (green), MyHC-IIB (red), and laminin (blue); unstained fibers (black) represent MyHC-IIA/IIX fibers $(A, l e f t)$. Soleus muscle with antibodies against CD31 (green), MyHC-I (red), and laminin (blue); unstained fibers (black) represent MyHC-IIA/IIB/ IIX fibers $(B, l e f t) . A$ and $B$, panels at right: fiber boundaries of the same section visualized by antilaminin (gray) and CD31 staining (black). Capillary density (CD) (capillaries per square millimeter) $(C)$, capillary contacts per square millimeter section CCD $(D)$, capillary perimeter $(\mathrm{CP})(\mu \mathrm{m})(E), \mathrm{FCSA}$ per capillary contact $\left(\mu \mathrm{m}^{2}\right)(F)$, and interstitial space between fibers $(G)$. Significant differences of normoxia (basal) values between muscles are indicated with \$; significant differences between groups at a given time point: $* P<0.05, * * / \$ \$ P \leq 0.01$, $\$ \$ \$ P \leq 0.001$ ( $n=6-8$ per group).
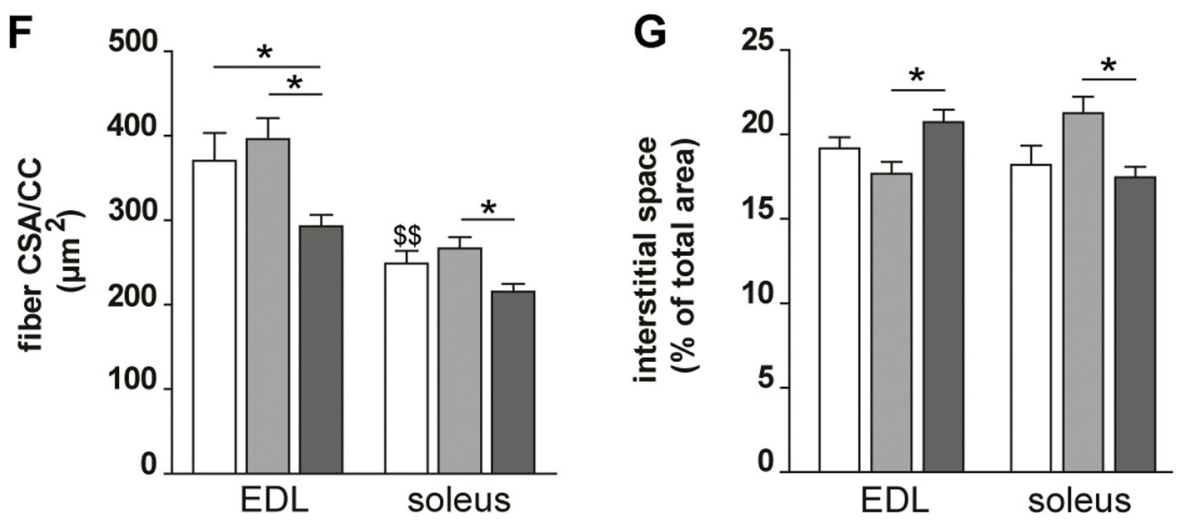

sensitivity to increased circulating corticosterone concentrations. Such an attenuated angiogenic response may well account for the poor adaptation of the capillary structure to hypoxia in glycolytic muscles. The CD was lower in glycolytic EDL than in oxidative soleus muscle confirming earlier studies (39). The resulting larger FCSA per capillary further predisposes the glycolytic EDL muscle to oxygen and nutrient deficiency. The hypoxia-induced reduction in muscle fiber diameter in the EDL may have partially compensated for the cited increases in sensitivity to hypoxia. In the oxidative soleus muscle, hypoxic conditions increased the number of $\mathrm{CC}$ per muscle fiber $(7,11)$, which reduces its sensitivity to hypoxia. The deep, more oxidative region of the plantaris muscle in rats also responded with an increase in capillarity to chronic hypoxia, whereas the superficial, more glycolytic region of the same muscle did not (58). These findings reveal two distinct structural changes to adapt to hypoxia, that is, via a decrease in fiber diameter (EDL) or an increase in CC per fiber. In patients with moderate to severe COPD, no difference of FCSA per capillary contact was observed, although the number of capillaries per fiber was decreased compared with controls, except for type IIB fibers (24). The loss of capillaries may be a 
long-term adaptive mechanism following the reduced FCSA observed in our relatively short-term study.

Increased protein turnover plays a role in muscle homeostasis under stress and does not necessarily result in severe muscle atrophy as long as the size of the stress falls within the adaptive capacity of the organism or cell. We showed in our previous article (10) that hypoxia stimulated both protein synthesis and degradation pathways. Furthermore, we showed that hypoxia activated the UPR without completely blocking mRNA translation. This may explain why the effects of severe hypoxia are relatively small in otherwise healthy mice. Similarly, it was recently shown that endoplasmic reticulum-stress and hypoxiaresponse pathways potentiated HIF-1 transcriptional activity of targets like VEGF (43), thereby promoting adaptation. In COPD patients, however, where stress due to multiple stressors probably exceeds the adaptive capacity, certainly in the long run, the outcome is muscle atrophy.

Limitations of the study. We have not analyzed the effects of hypoxia-mediated inactivity, which may also contribute to muscle atrophy. We cannot exclude that hypoxia-associated inactivity contributes to the hypoxia-specific reduction in FCSA of IIB fibers found in our study. However, muscle unloading in rodents usually results in type I fiber atrophy. It has been shown that short-term hypoxia $\left(10 \% \mathrm{O}_{2}\right.$ for 2.5 days $)$ resulted in clearly decreased activity levels (4), but the effects of chronic hypoxia on activity were not investigated in that study. Our hypoxic mice seemed drowsy during the first week of the experiment, but we noticed no obvious differences in activity with the normoxic group at later time points.

\section{CONCLUSION}

This study shows that hypoxia-induced muscle atrophy is more prominent in the glycolytic EDL than the oxidative soleus muscle. The atrophy observed in the EDL contained a hypoxia-specific effect that was independent of food intake, which involved activation of the catabolic proteasomal and lysosomal protein degradation pathways as well as increased expression of the glucocorticoid receptor gene and its target genes. Both muscles adapted to hypoxia by a decrease of the fiber volume supported by one capillary contact, but this was achieved by a decrease in muscle fiber size in the EDL and an increase in the number of CC in the soleus muscle. The more pronounced atrophic response of glycolytic fibers in mice suggests that COPD patients may be more susceptible to hypoxia-induced muscle atrophy because of the predominance of glycolytic fibers in their muscles.

\section{ACKNOWLEDGMENTS}

The authors gratefully acknowledge the technical support provided by Els Terwindt, Paul van Dijk, Greet Mommen, Patricia Niedoba, Marleen Hendriks, and Aafke Duisters.

\section{GRANTS}

This study was performed within the framework of the Dutch Top Institute Pharma, project T1-201. Partners in this project are Maastricht University Medical Center+, University Medical Center Groningen, University Medical Center Utrecht, GlaxoSmithKline, AstraZeneca, Nycomed, and Danone Research.

\section{DISCLOSURES}

No conflicts of interest, financial or otherwise, are declared by the author(s).

\section{AUTHOR CONTRIBUTIONS}

C.C.d.T. performed experiments; C.C.d.T. analyzed data; C.C.d.T., R.C.L., W.H.L., H.R.G., A.M.S., and S.E.K. interpreted results of experiments; C.C.d.T. prepared figures; C.C.d.T. drafted manuscript; C.C.d.T., R.C.L., W.H.L., H.R.G., A.M.S., and S.E.K. approved final version of manuscript; R.C.L., W.H.L., A.M.S., and S.E.K. conception and design of research; R.C.L., W.H.L., H.R.G., A.M.S., and S.E.K. edited and revised manuscript.

\section{REFERENCES}

1. Batt J, Ahmed SS, Correa J, Bain A, Granton J. Skeletal muscle dysfunction in idiopathic pulmonary arterial hypertension. Am J Resp Cell Mol Biol 50: 74-86, 2014.

2. Bellot G, Garcia-Medina R, Gounon P, Chiche J, Roux D, Pouysségur J, Mazure NM. Hypoxia-induced autophagy is mediated through hypoxia-inducible factor induction of BNIP3 and BNIP3L via their BH3 domains. Mol Cell Biol 29: 2570-2581, 2009.

3. BioGPS. VEGF-A gene expression profile. http://biogps.org/-goto= generreport\&id=7422 [6 Dec. 2014].

4. Bishop B, Silva G, Krasney J, Nakano H, Roberts A, Farkas G, Rifkin D, Shucard D. Ambient temperature modulates hypoxic-induced changes in rat body temperature and activity differentially. Am J Physiol Regul Integr Comp Physiol 280: R1190-R1196, 2001.

5. Boutellier U, Howald H, di Prampero PE, Giezendanner D, Cerretelli P. Human muscle adaptations to chronic hypoxia. Prog Clin Biol Res 136: 273-285, 1983.

6. Bredman JJ, Wessels A, Weijs WA, Korfage JA, Soffers CA, Moorman AF. Demonstration of 'cardiac-specific' myosin heavy chain in masticatory muscles of human and rabbit. Histochem $J$ 23: 160-170, 1991.

7. Breen E, Tang K, Olfert M, Knapp A, Wagner P. Skeletal muscle capillarity during hypoxia: VEGF and its activation. High Alt Med Biol 9: 158-166, 2008.

8. Burkholder TJ, Fingado B, Baron S, Lieber RL. Relationship between muscle fiber types and sizes and muscle architectural properties in the mouse hindlimb. J Morphol 221: 177-190, 1994.

9. Decramer M, De Benedetto F, Del Ponte A, Marinari S. Systemic effects of COPD. Respir Med 99 Suppl B: S3-S10, 2005.

10. de Theije CC, Langen RC, Lamers WH, Schols AM, Koehler SE. Distinct responses of protein turnover-regulatory pathways in hypoxiaand semi-starvation-induced muscle atrophy. Am J Physiol Lung Cell Mol Physiol 305: L82-L91, 2013.

11. Deveci D, Marshall JM, Egginton S. Relationship between capillary angiogenesis, fiber-type, and fiber size in chronic systemic hypoxia. Am J Physiol Heart Circ Physiol 281: H241-H252, 2001.

12. Eliason G, Abdel-Halim SM, Piehl-Aulin K, Kadi F. Alterations in the muscle-to-capillary interface in patients with different degrees of chronic obstructive pulmonary disease. Respir Res 11: 97, 2010.

13. Gamboa JL, Garcia-Cazarin ML, Andrade FH. Chronic hypoxia increases insulin-stimulated glucose uptake in mouse soleus muscle. Am J Physiol Regul Integr Comp Physiol 300: R85-R91, 2011.

14. Glass DJ. Skeletal muscle hypertrophy and atrophy signaling pathways. Int J Biochem Cell Biol 37: 1974-1984, 2005.

15. Gomes MD, Lecker SH, Jagoe RT, Navon A, Goldberg AL. Atrogin-1, a muscle-specific F-box protein highly expressed during muscle atrophy. Proc Natl Acad Sci U S A 98: 14440-14445, 2001.

16. Gosker HR, Engelen MPKJ, van Mameren H, van Dijk PJ, van der Vusse GJ, Wouters EFM, Schols AMWJ. Muscle fiber-type IIX atrophy is involved in the loss of fat-free mass in chronic obstructive pulmonary disease. Am J Clin Nutr 76: 113-119, 2002.

17. Gosker HR, van Mameren H, van Dijk PJ, Engelen MP, van der Vusse GJ, Wouters EF, Schols AM. Skeletal muscle fibre-type shifting and metabolic profile in patients with chronic obstructive pulmonary disease. Eur Respir J 19: 617-625, 2002.

18. Gosker HR, Zeegers MP, Wouters EF, Schols AM. Muscle fibre type shifting in the vastus lateralis of patients with COPD is associated with disease severity: a systematic review and meta-analysis. Thorax 62: 944-949, 2007.

19. Gray S, Wang B, Orihuela Y, Hong EG, Fisch S, Haldar S, Cline GW, Kim JK, Peroni OD, Kahn BB, Jain MK. Regulation of gluconeogenesis by Kruppel-like factor 15. Cell Metab 5: 305-312, 2007.

20. Gray-Donald K, Gibbons L, Shapiro SH, Macklem PT, Martin JG. Nutritional status and mortality in chronic obstructive pulmonary disease. Am J Resp Crit Care Med 153: 961-966, 1996. 
21. Herridge MS, Cheung AM, Tansey CM, Matte-Martyn A, DiazGranados N, Al-Saidi F, Cooper AB, Guest CB, Mazer CD, Mehta S, Stewart TE, Barr A, Cook D, Slutsky AS. One-year outcomes in survivors of the acute respiratory distress syndrome. N Engl J Med 348: 683-693, 2003.

22. Hickson RC, Wegrzyn LE, Osborne DF, Karl IE. Glutamine interferes with glucocorticoid-induced expression of glutamine synthetase in skeletal muscle. Am J Physiol Endocrinol Metab 270: E912-E917, 1996.

23. Itoh K, Moritani T, Ishida K, Hirofuji C, Taguchi S, Itoh M. Hypoxiainduced fibre type transformation in rat hindlimb muscles. Histochemical and electro-mechanical changes. Eur J Appl Physiol Occup Physiol 60: 331-336, 1990.

24. Jobin J, Maltais F, Doyon JF, LeBlanc P, Simard PM, Simard AA, Simard C. Chronic obstructive pulmonary disease: capillarity and fibertype characteristics of skeletal muscle. J Cardiopulm Rehabil 18: 432437, 1998.

25. Klionsky DJ, et al. Guidelines for the use and interpretation of assays for monitoring autophagy. Autophagy 8: 445-544, 2012.

26. Kon M, Ohiwa N, Honda A, Matsubayashi T, Ikeda T, Akimoto T, Suzuki Y, Hirano Y, Russell AP. Effects of systemic hypoxia on human muscular adaptations to resistance exercise training. Physiol Reports 2: e12033, 2014.

27. Koncarevic A, Jackman RW, Kandarian SC. The ubiquitin-protein ligase Nedd4 targets Notch1 in skeletal muscle and distinguishes the subset of atrophies caused by reduced muscle tension. Faseb $J$ 21: 427-437, 2007.

28. Krock BL, Skuli N, Simon MC. Hypoxia-induced angiogenesis: good and evil. Genes Cancer 2: 1117-1133, 2011.

29. Lainscak M, von Haehling S, Doehner W, Sarc I, Jeric T, Ziherl K, Kosnik M, Anker SD, Suskovic S. Body mass index and prognosis in patients hospitalized with acute exacerbation of chronic obstructive pulmonary disease. J Cachexia Sarcopenia Muscle 2: 81-86, 2011.

30. Leonard MO, Godson C, Brady HR, Taylor CT. Potentiation of glucocorticoid activity in hypoxia through induction of the glucocorticoid receptor. J Immunol 174: 2250-2257, 2005.

31. Livingstone I, Johnson MA, Mastaglia FL. Effects of dexamethasone on fibre subtypes in rat muscle. Neuropathol Appl Neurobiol 7: 381-398, 1981.

32. Lunde IG, Anton SL, Bruusgaard JC, Rana ZA, Ellefsen S, Gundersen K. Hypoxia inducible factor 1 links fast-patterned muscle activity and fast muscle phenotype in rats. $J$ Physiol 589: 1443-1454, 2011.

33. Ma K, Mallidis C, Bhasin S, Mahabadi V, Artaza J, GonzalezCadavid N, Arias J, Salehian B. Glucocorticoid-induced skeletal muscle atrophy is associated with upregulation of myostatin gene expression. Am J Physiol Endocrinol Metab 285: E363-E371, 2003.

34. Macpherson PC, Wang X, Goldman D. Myogenin regulates denervation-dependent muscle atrophy in mouse soleus muscle. J Cell Biochem 112: 2149-2159, 2011.

35. Mador MJ, Bozkanat E. Skeletal muscle dysfunction in chronic obstructive pulmonary disease. Respir Res 2: 216-224, 2001.

36. Max SR, Thomas JW, Banner C, Vitkovic L, Konagaya M, Konagaya Y. Glucocorticoid receptor-mediated induction of glutamine synthetase in skeletal muscle cells in vitro. Endocrinology 120: 1179-1183, 1987.

37. Mendias CL, Marcin JE, Calerdon DR, Faulkner JA. Contractile properties of EDL and soleus muscles of myostatin-deficient mice. $J$ Appl Physiol (1985) 101: 898-905, 2006.

38. Mizushima N, Ohsumi Y, Yoshimori T. Autophagosome formation in mammalian cells. Cell Struct Funct 27: 421-429, 2002.

39. Murakami S, Fujino H, Takeda I, Momota R, Kumagishi K, Ohtsuka A. Comparison of capillary architecture between slow and fast muscles in rats using a confocal laser scanning microscope. Acta Medica Okayama 64: 11-18, 2010

40. Natanek SA, Riddoch-Contreras J, Marsh GS, Hopkinson NS, Moxham J, Man WD, Kemp PR, Polkey MI. MuRF-1 and Atrogin-1 protein expression and quadriceps fiber size and muscle mass in stable patients with COPD. COPD 10: 618-624, 2013.
41. Nauck M, Karakiulakis G, Perruchoud AP, Papakonstantinou E, Roth M. Corticosteroids inhibit the expression of the vascular endothelial growth factor gene in human vascular smooth muscle cells. Eur J Pharmacol 341: 309-315, 1998.

42. Park CW, Ryu KY. Cellular ubiquitin pool dynamics and homeostasis. BMB Rep 47: 475-482, 2014.

43. Pereira ER, Frudd K, Awad W, Hendershot LM. Endoplasmic reticulum (ER) stress and hypoxia response pathways interact to potentiate hypoxia-inducible factor 1 (HIF-1) transcriptional activity on targets like vascular endothelial growth factor (VEGF). J Biol Chem 289: 3352-3364, 2014.

44. Pereira MC, Isayama RN, Seabra JC, Campos GE, Paschoal IA. Distribution and morphometry of skeletal muscle fibers in patients with chronic obstructive pulmonary disease and chronic hypoxemia. Muscle Nerve 30: 796-798, 2004.

45. Regula KM, Ens K, Kirshenbaum LA. Inducible expression of BNIP3 provokes mitochondrial defects and hypoxia-mediated cell death of ventricular myocytes. Circ Res 91: 226-231, 2002.

46. Roy RR, Gardiner PF, Simpson DR, Edgerton VR. Glucocorticoidinduced atrophy in different fibre types of selected rat jaw and hind-limb muscles. Arch Oral Biol 28: 639-643, 1983.

47. Sandri M. Autophagy in skeletal muscle. FEBS Lett 584: 1411-1416, 2010.

48. Sato S, Suzuki H, Tsujimoto H, Shirato K, Tachiyashiki K, Imaizumi K. Casted-immobilization downregulates glucocorticoid receptor expression in rat slow-twitch soleus muscle. Life Sci 89: 962-967, 2011.

49. Schakman O, Kalista S, Barbe C, Loumaye A, Thissen JP. Glucocorticoid-induced skeletal muscle atrophy. Int J Biochem Cell Biol 45: 2163-2172, 2013

50. Shimizu N, Yoshikawa N, Ito N, Maruyama T, Suzuki Y, Takeda Si Nakae J, Tagata Y, Nishitani S, Takehana K, Sano M, Fukuda K, Suematsu M, Morimoto C, Tanaka H. Crosstalk between glucocorticoid receptor and nutritional sensor mTOR in skeletal muscle. Cell Metab 13: 170-182, 2011.

51. Soguel Schenkel N, Burdet L, de Muralt B, Fitting JW. Oxygen saturation during daily activities in chronic obstructive pulmonary disease. Eur Respir J 9: 2584-2589, 1996.

52. Stavreva DA, Varticovski L, Hager GL. Complex dynamics of transcription regulation. Biochim Biophys Acta 1819: 657-666, 2012.

53. van den Borst B, Schols AM, de Theije C, Boots AW, Köhler SE, Goossens GH, Gosker HR. Characterization of the inflammatory and metabolic profile of adipose tissue in a mouse model of chronic hypoxia. J Appl Physiol 114: 1619-1628, 2013.

54. Vilar J, Waeckel L, Bonnin P, Cochain C, Loinard C, Duriez M, Silvestre JS, Levy BI. Chronic hypoxia-induced angiogenesis normalizes blood pressure in spontaneously hypertensive rats. Circ Res 103: 761-769, 2008.

55. Watson ML, Baehr LM, Reichardt HM, Tuckermann JP, Bodine SC, Furlow JD. A cell-autonomous role for the glucocorticoid receptor in skeletal muscle atrophy induced by systemic glucocorticoid exposure. Am J Physiol Endocrinol Metab 302: E1210-E1220, 2012.

56. Weckbach LT, Groesser L, Borgolte J, Pagel JI, Pogoda F, Schymeinsky J, Muller-Hocker J, Shakibaei M, Muramatsu T, Deindl E, Walzog B. Midkine acts as proangiogenic cytokine in hypoxia-induced angiogenesis. Am J Physiol Heart Circ Physiol 303: H429-H438, 2012.

57. Wouters EF. Nutrition and metabolism in COPD. Chest 117: 274S-280S, 2000.

58. Wust RC, Jaspers RT, van Heijst AF, Hopman MT, Hoofd LJ, van der Laarse WJ, Degens H. Region-specific adaptations in determinants of rat skeletal muscle oxygenation to chronic hypoxia. Am J Physiol Heart Circ Physiol 297: H364-H374, 2009.

59. Zhang H, Bosch-Marce M, Shimoda LA, Tan YS, Baek JH, Wesley JB, Gonzalez FJ, Semenza GL. Mitochondrial autophagy is an HIF-1dependent adaptive metabolic response to hypoxia. J Biol Chem 283: 10892-10903, 2008. 